\title{
Visual Investigation of the Occurrence Characteristics of Multi-Type Formation Water in a Fracture-Cavity Carbonate Gas Reservoir
}

\author{
Lu Wang ${ }^{1}$, Shenglai Yang ${ }^{1, *}$, Xian Peng ${ }^{2}$, Hui Deng ${ }^{2}$, Yi Liao ${ }^{3}$, Yicheng Liu ${ }^{2}$, Wei $\mathrm{Xu}^{2}$ and \\ Youjun Yan ${ }^{2}$ \\ 1 State Key Laboratory of Petroleum Resources and Prospecting, China University of Petroleum-Beijing, \\ Beijing 102249, China; wlhmhxydh@163.com \\ 2 Exploration and Development Research Institute of Southwest Oil \& Gas Field Company, PetroChina, \\ Chengdu 610041, China; pengxian_petro@126.com (X.P.); denghui_petro@126.com (H.D.); \\ liuyicheng_petro@126.com (Y.L.); xuwei_petro@163.com (W.X.); yanyoujun_petro@sina.com (Y.Y.) \\ 3 Shunan Division of Southwest Oil \& Gas Field Company, PetroChina, Luzhou 646000, China; \\ liaoyilushi@petrochina.com.cn \\ * Correspondence: yangs103@163.com; Tel.: +86-010-8973-2268
}

Received: 23 February 2018; Accepted: 14 March 2018; Published: 15 March 2018

\begin{abstract}
It is difficult to investigate the formation process and occurrence states of water in multi-type reservoirs, due to the strong heterogeneity and complex microstructure of the fracture-cavity carbonate gas reservoirs. To date, there is no systematic study on the occurrence characteristics of multi-type formation water, especially through visual observation experiments. In this paper, a new creation method for visual micromodels based on CT scan images and microelectronic photolithography techniques was described. Subsequently, a gas-drive-water visual experiment was conducted to intuitively study the formation mechanism and the occurrence states of formation water. Then, the ImageJ gray analysis method was utilized to quantitatively investigate the gas-water saturation and the proportion of residual water film. Finally, the occurrence characteristics of formation water and its effects on gas seepage flow were comprehensively analyzed. Visual experimental results showed that: the migration processes of natural gas in different types of reservoirs are different; the water in multiple media consists of native movable water and residual water, and residual water is composed of secondary movable water and irreducible water; the residual water mainly occurs in different locations of different reservoirs with the forms of "water film", "water mass", "water column" and "water droplets"; the main influencing factors are capillary force, surface tension, displacement pressure and channel connectivity. Quantitative results reflect that the saturation of movable water and residual water are the parameters related directly to reservoir physical properties, pore structure and displacement pressure-the smaller the size of flow channel, the larger the space occupied by water film; the thickness proportion of water film is increasing exponentially with the channel size; the thickness proportion of water film decreases as the increase of displacement pressure; the thickness proportion of water film is essentially constant when the displacement pressure increases to a certain extent. The conducted visual investigation not only improves our intuitive understanding of the occurrence characteristics of formation water, but also provides a theoretical basis for the efficient development of fracture-cavity gas reservoirs.
\end{abstract}

Keywords: visual experiment; ImageJ gray analysis; occurrence characteristics; residual water; irreducible water; fracture-cavity carbonate gas reservoir 


\section{Introduction}

Carbonate reservoirs play a crucial role in the production and world reserves of oil and gas, water, and other mineral resources. The fluid flow mechanism in these reservoirs is of interest to petroleum engineers, geothermal engineers, and geologists. Significant progress has been achieved over the past few decades in terms of understanding and modeling the seepage processes in carbonate rock [1]. However, most studies are focused mainly on fracture carbonate reservoirs, ignoring the cavities and the combination media of pore-cavity-fracture in rocks. A number of fracture-cavity carbonate gas reservoirs has been found worldwide and have become an important global natural gas supply resource. They have the characteristics of complex structures, strong heterogeneity, macroscopic development of pore-fracture-pore, and complicated seepage laws [2-6]. These characteristics are different from those of conventional reservoirs, making the occurrence states and seepage characteristics of formation water in multi-type reservoirs complicated.

In recent years, the investigations on gas-water two-phase flow has aroused the concern of scholars and engineers. Understanding the occurrence characteristics and flow laws of formation water in gas reservoirs has become the key to enhanced natural gas recovery. However, most studies on the occurrence of formation water are concentrated in the low-permeability and tight sandstone gas reservoirs, and the conventional investigation methods are displacement experiment, magnetic resonance imaging (MRI) and mercury penetration. Hu et al. [7] reported that the formation water in low-permeability gas reservoirs consists of movable water and residual water, and the physical properties and pressure are the main influencing factors of the occurrence state. Wang et al. [8] revealed that the formation water in tight sandstone gas reservoirs is composed of irreducible water, capillary water and free water. Zhu et al. $[9,10]$ concluded that the occurrence state of formation water in tight reservoirs is determined by the physical properties, pore structure and gas flow model. Although these studies reported some achievements, they can only predict the occurrence characteristics of formation water in singular reservoirs by analyzing experimental curves. Furthermore, the common methods of studying gas-water two-phase flow characteristics, such as gas-water saturation and flow capability, are core flooding experiments and numerical simulations. For example, Li et al. [11] tested the gas-water permeability in full diameter cores to analyze the features of gas-water relative permeability curves and gas well inflow dynamics. Xiao et al. [12-14] derived an analytical model considering saturation of water and tortuosity fractal dimension to predict the capillary pressure and relative water permeability of unsaturated porous rocks. However, no fundamental study has been conducted for visualizing the dynamic characterization of formation water in multi-type media at a micro level.

Currently, various types of microscopic visual models have been widely utilized to investigate the multiphase flow characteristics and oil recovery mechanism at the micro scale because they can structurally simulate the porous structure of oil or gas reservoirs [15-18]. The prominent advantage of micromodels is that they allow the direct visualization of different multiphase fluid flow phenomena in porous media. Mattax and Kyte [19] first created visual micromodels with a regular network of channels. Then, several studies improved the creation method to make the suitable micromodels for different applications. Recently, Mohammad et al. $[18,20]$ fabricated dual-porosity visual micromodels by adding random fractures to regular pore structures. However, all the micromodels reported in the previous studies refer to the base images of uniformly or randomly patterned structures, which cannot fully depict the actual reservoir structures. Therefore, investigations of the characteristics of multiphase flow and other aspects in multi-type reservoirs are not systematic and comprehensive.

Microscopic visual models have been applied as new multi-functional simulation physics models to the field of petroleum engineering, and have been generally accepted by many scholars [21]. Thess model can not only fundamentally investigate the mechanism or effect of various enhanced oil recovery (EOR), including water flooding [22], gels for conformance control [23], steam flooding [24], foam flooding [25], microbial EOR [26], carbonated water flooding [27], solution gas driving [28], miscible displacement [29], and spontaneous imbibition [30], but also intuitively 
describe the essential aspects of multiple fluid or rock-fluid interactions in porous media, including asphaltene deposition [31], capillary force [32], polymer retention [33], wettability [34], interfacial tension [35], and multiple-contact miscibility [36]. However, there is no visualization study on the occurrence characteristics of formation water in porous media, especially for the multi-type media of fracture-cavity carbonate gas reservoirs.

The purpose of our study is to intuitively investigate the formation mechanism and occurrence states of formation water. In this paper, three types of micromodels (fracture, cavity, and fracture-cavity type) were primarily designed and constructed using a technique involving a combination of CT scanning and microelectronic photolithography, which could approximately replicate the microstructures of fracture-cavity carbonate gas reservoirs. Subsequently, two-dimensional gas-drive-water visual experiments were conducted to observe the process of gas-water flow by gas injection. Next, the formation mechanism and occurrence states of multi-type residual water was intuitively investigated based on the visual images. Then, the ImageJ gray analysis method was used to quantitatively study the gas-water saturation and residual water film ratio under different differential pressures. Finally, the effects of formation water on gas seepage capability were synthetically analyzed based on the study results.

\section{Materials and Methods}

\subsection{Similarity Principle}

The similarity principle is the most important prerequisite for physical simulation experiments. According to the requirements of similarity principle in visual simulation experiment, five aspects of similarities were designed:

(1) Similarity in microstructures and heterogeneity: three types visual micromodels with representative microstructures were designed and fabricated based on the CT images of three typical cores in study area.

(2) Similarity in wettability: float glass with similar wettability and wetting angles to the study area rocks was chosen to construct the visual micromodel.

(3) Similarity in formation conditions: customized holder and constant temperature oven for the visual micromodels were used to simulate the formation conditions.

(4) Similarity in flow mode: gas-drive-water physical simulation experiments were conducted to simulate the formation process of formation water in gas reservoir according to the theory of hydrocarbon migration and accumulation.

(5) Similarity in fluid properties: water used in the visual experiment was prepared according to the chemical composition of formation water, and gas used in the visual experiment was produced by an actual gas well.

\subsection{Visual Micromodels}

Glass micromodels can be used for visualization and simulation of two-dimensional seepage processes in oil and gas reservoirs. The application of these micromodels can facilitate to get an enhanced insight into the formation mechanism of remaining oil, trapped gas and residual water, thus providing a theoretical basis for enhancing oil or gas recovery. The development of improved micromodels presented in this paper consists of the mask creation based on CT scanning images and the micromodel fabrication based on microelectronic photolithography, which have never been reported in previous studies.

\subsubsection{Mask Creation Based on CT Scan Images}

Mask creation is one of the most important processes in visual micromodel fabrication, because the creation level of mask directly influences the accuracy and complexity of microstructures. Mask 
creation starts by depicting a base image that allows for some digital modification to improve the characteristics and connectivity of the microstructure. In order to fully simulate the microstructure characteristics and distribution of pore-cavity-fracture in reservoir rocks, the Micro XCT-400 CT scanner (Xradia Corporation, Concord, CA, USA) was used to obtain the base images for the three types of reservoirs. The voltage and power of the CT scanner is $40-150 \mathrm{kV}$ and $1-10 \mathrm{~W}$. Each CT scan image is $1778 \times 1800$ pixels, with a pixel size of $13.15 \mu \mathrm{m}$. The photographs and petrophysical properties of the scanned cores are presented in Table 1 and Figure 1, respectively. These core samples were obtained from the Anyue Gasfield in Southwest China, a typical fracture-cavity carbonate gas reservoir. Through the screening and extraction of more than $6000 \mathrm{CT}$ scan images, three types of images with evident structure characteristics and complex distribution of pore-cavity-fracture, as shown in Figure 2, were selected as the base images.

Table 1. Petrophysical properties of cores.

\begin{tabular}{|c|c|}
\hline Core Number & Length $(\mathrm{cm})$ \\
\hline 201400270147 & 4.384 \\
\hline 201400830059 & 4.900 \\
\hline 201400830021 & 4.560 \\
\hline
\end{tabular}

(a)

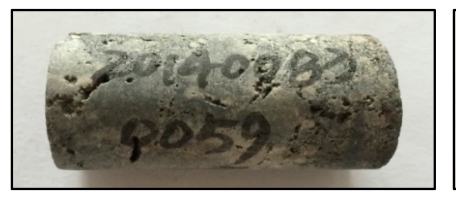

(b)

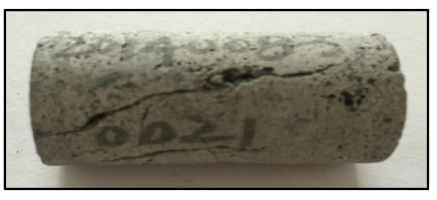

(c)

Figure 1. Photographs of cores. (a) 201400270147; (b) 201400830059; (c) 201400830021.

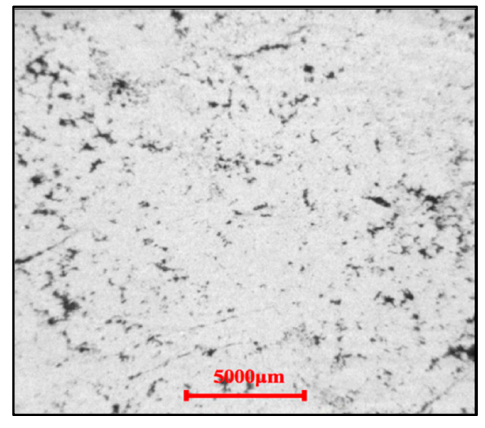

(a)

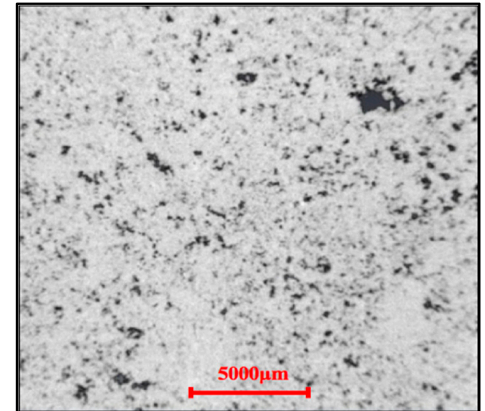

(b)

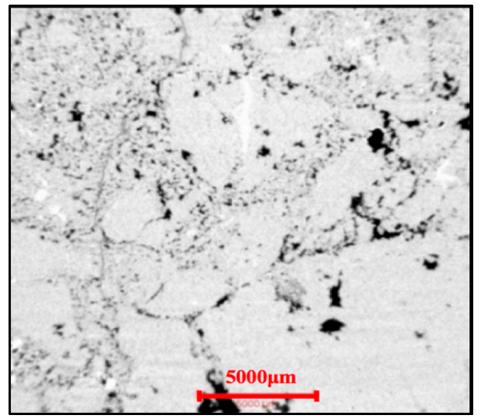

(c)

Figure 2. Optimized CT scan images: (a) Fracture-type; (b) Cavity-type; (c) Fracture-cavity-type.

Once the base images were selected, they were converted to binary images by setting the threshold of the gray value. Referring to the 3D CT scan images, the ineffective pores in the porous media were 
removed, and the fractures or throats isolated in the 2D images were reconnected manually. In these binary images, white pixels correspond to the rock matrix whereas black pixels represent the porous media. After the binary images were modified, the creation of the mask frame diagram continued. Figure 3 shows that channels were added along the entire length of the inlet and outlet sides of the micromodel. Furthermore, several ports were added in the channels which can permit fluids flow into and out of the valid region. This improved design can promote flow communication and guarantees a linear flow boundary condition. Compared with the traditional boundary condition of one point, the displacement process simulated by linear flow boundary condition is more consistent with the actual situation. The pixel size of the base image must be enlarged on condition that the heterogeneity and relative pore-size distribution remain constant, because of the resolution limitation of the Computer Numerical Control (CNC) milling machine. Three types of base images made by the Corel Draw X8 software (Corel Corporation, Ottawa, Canada) are presented in Figure 4.

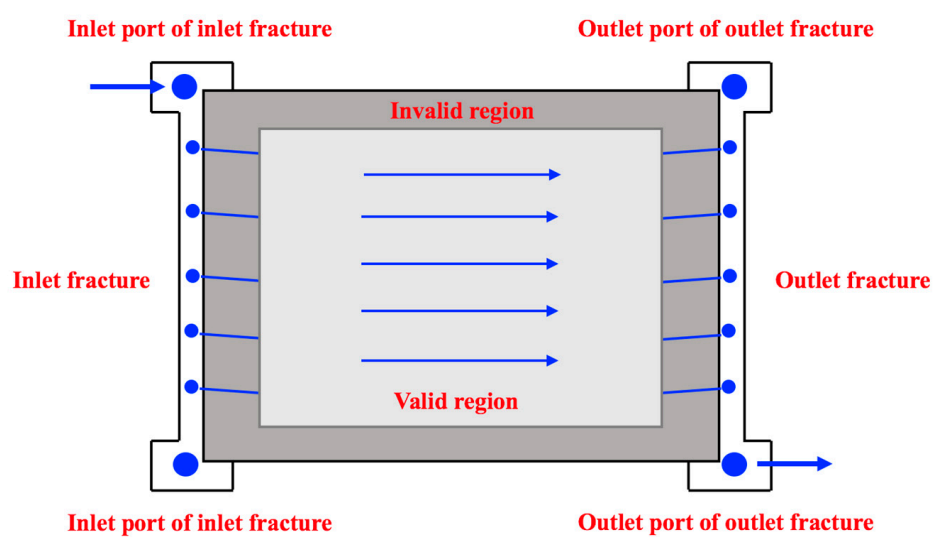

Figure 3. Schematic of the mask frame and typical flow direction.

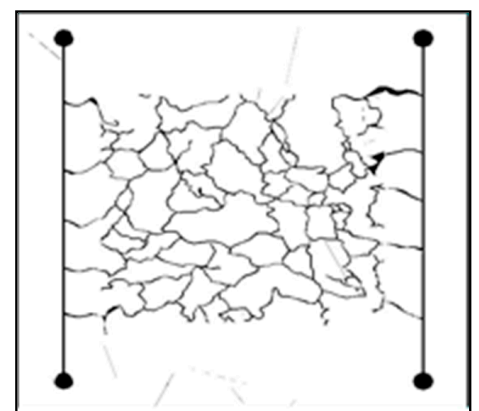

(a)

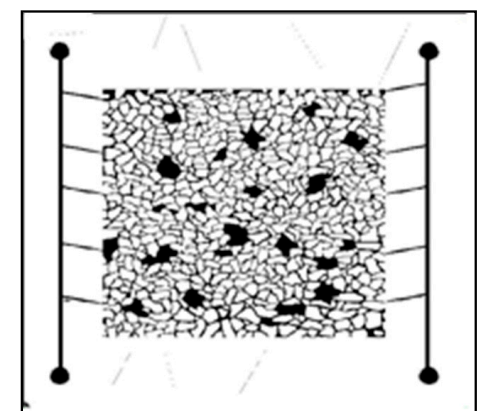

(b)

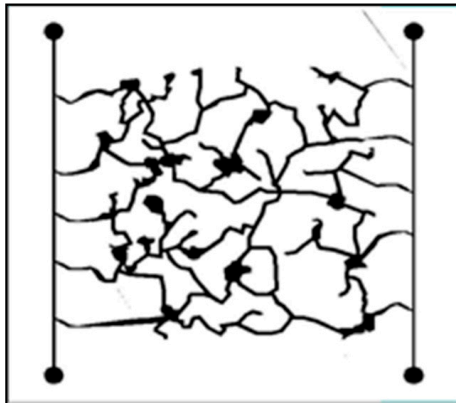

(c)

Figure 4. Base images of three type cores based on CT scan images: (a) Fracture-type; (b) Cavity-type; (c) Fracture-cavity-type. 


\subsubsection{Micromodel Fabrication Based on Microelectronic Photolithography Techniques}

A float glass was used as the glass substrate to construct the micromodel, because of its favorable flatness, suitable transparency, and satisfying durability during etching. The micromodel fabrication process includes pretreatment, etching, cleaning, bonding, and testing, as depicted in Figure 5. The fabrication procedure for each micromodel is the same, except that the mask is changed according to the different base images. In addition, the duration of acid etching is changed depending on the desired etch depth. After the glasses were cooled down, the resistance to pressure and the sealability to fluids are tested to guarantee that the micromodels are qualified for the visual simulation experiment of gas-water flow. Figure 6 shows the three types of fabricated visual micromodels, and the model dimension is $6.0 \times 6.0 \mathrm{~cm}$. The diameter ranges of pores, cavities and fractures are $0.099-0.181 \mathrm{~mm}$, $1.161-1.657 \mathrm{~mm}$ and $0.325-0.492 \mathrm{~mm}$, respectively. The maximum allowable stress can up to $10 \mathrm{MPa}$ The contact angle of these micromodels is $36.4^{\circ}-36.7^{\circ}$ (water-wet), which is similar to the water-wet carbonate rocks in study area [37].

(a)

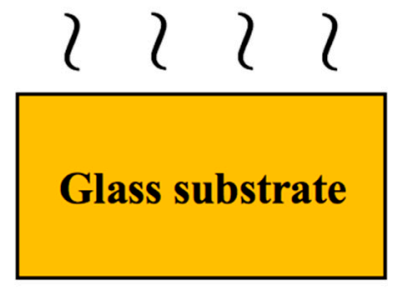

(d) DUV light
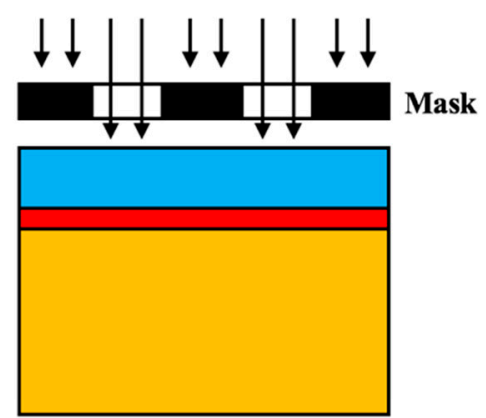

$(\mathbf{g})$

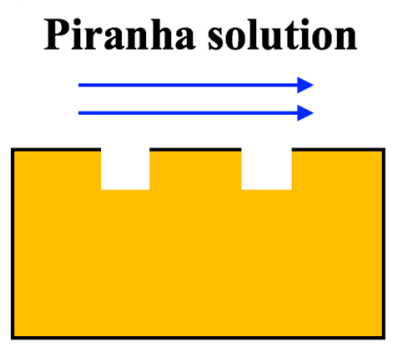

(b)

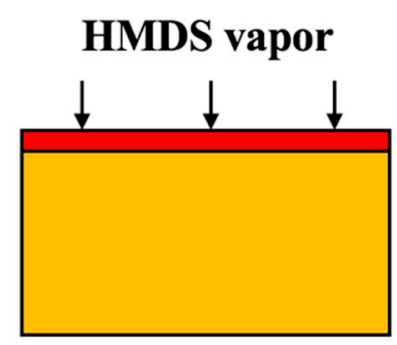

(e)

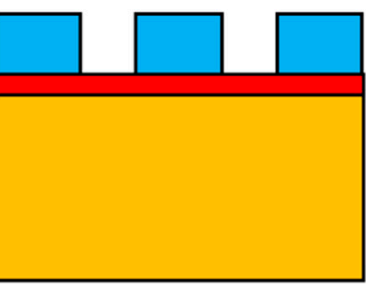

(h)

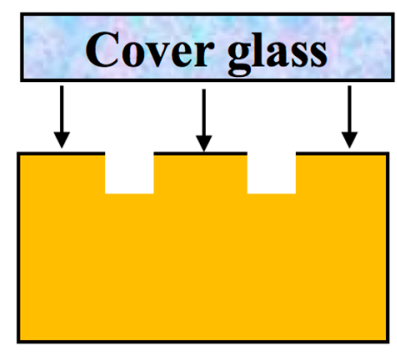

(c) High-speed spin

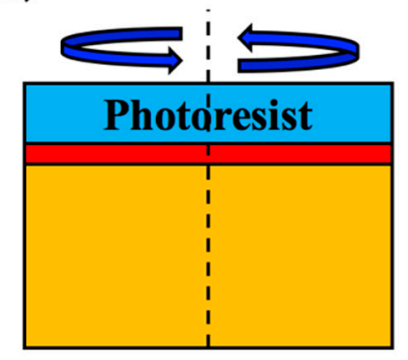

(f)

\section{HF acid gases}

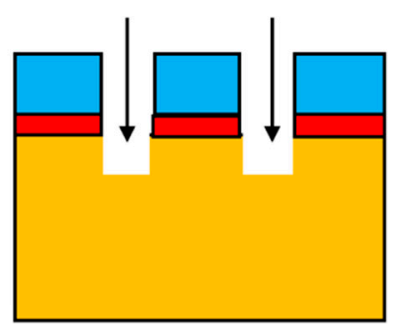

(i)

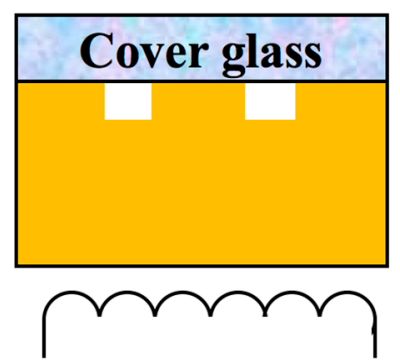

Figure 5. Visual micromodel fabrication process: (a) pretreatment (pre-baking and cleaning); (b) priming HMDS; (c) photoresist spin coating; (d) DUV exposure; (e) developing; (f) etching by HF acid gases; (g) cleaning by piranha solution; (h) bounding; and (i) heating. 


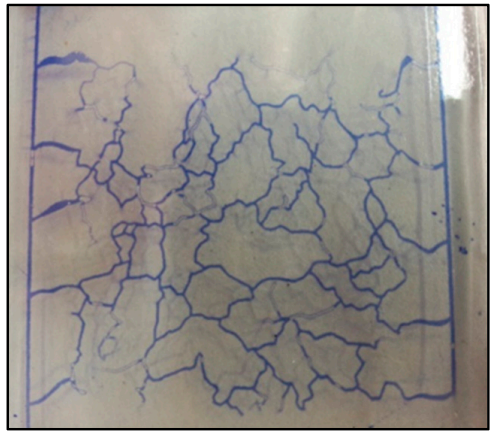

(a)

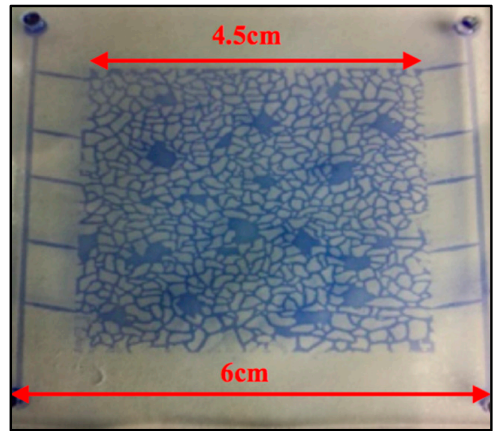

(b)

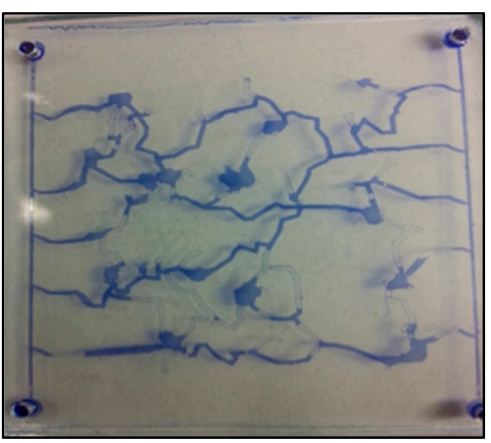

(c)

Figure 6. Fabricated visual micromodels based on the microelectronic photolithography technique:

(a) Fracture-type; (b) Cavity-type; (c) Fracture-cavity-type.

\subsubsection{Advantage of Microscopic Visual Models}

Compared with the traditional visualization models, the improved micromodel based on the combined technique of CT scan and microelectronic photolithography has the more advantages:

(1) Micromodel sealability is further enhanced by improving the bonding technique, guaranteeing the micromodel can be used for the simulation of gas-water flow under a certain stress.

(2) Microstructure characteristics and multi-type media distribution are similar to those of actual reservoirs, which can be used for intuitively studying the occurrence states of formation water after gas-drive-water procedure.

(3) Highest allowable stress of the micromodel is increased to $10 \mathrm{MPa}$, which is more close to the effective stress of actual reservoir.

(4) Three types of micromodels are fabricated according to the different type reservoirs of fracture-cavity carbonate gas reservoir, which have never been created and introduced in previous studies.

\subsection{Experimental Apparatus and Fluids}

A two-dimensional visual experimental investigation of gas-drive-water was conducted. The experimental apparatus is composed of a displacement system, data acquisition system and visualization system [38-41]. The schematic of experimental system is presented in Figure 7. The displacement system is composed of a 260D syringe pump (Teledyne ISCO, Thousand Oaks, CA, USA) that provides constant pressure, a natural gas tank, a formation water tank, a back-pressure pump, a storage tank, a back valve, and several pressure sensors. The data acquisition system consists a high-resolution microscopic camera (Infinity 3-6UR HLOT, Carlsbad, CA, USA) for capturing local microscopic images precisely, thereby enabling further investigation on the gas-water flow characteristics in multi-type media; a digital video (DV) for recording the overall flow process of the micromodel, thereby enabling further quantitative characterization of the visualized image at 
different times; a backlight and a reflector for improving the quality of images and videos; temperature sensors; pressure sensors; a data collector; and a computer. The visualization system includes a micromodel holder, a constant temperature oven, and three types of micromodels. Except for the visual micromodel, the customized micromodel holder is the most important apparatus. This holder (see Figure 8) has two fluid injection ports and two fluid production ports that correspond to the ports on the micromodel, and the micromodel can be fastened to the stainless frame. O-rings are used around the four ports to improve the sealability of the micromodel holder. The experimental water was prepared in laboratory according to the chemical composition of formation water in our study area. The mineralization degree is $106,241 \mathrm{mg} / \mathrm{L}$ and the water type is $\mathrm{CaCl}_{2}$. The experimental gas was a natural gas produced by an actual gas well in Southwest China, and its composition and properties are presented in Table 2. In order to distinguish the experimental water from the colorless natural gas in the images, the experimental water should be dyed blue by a methyl dye reagent.

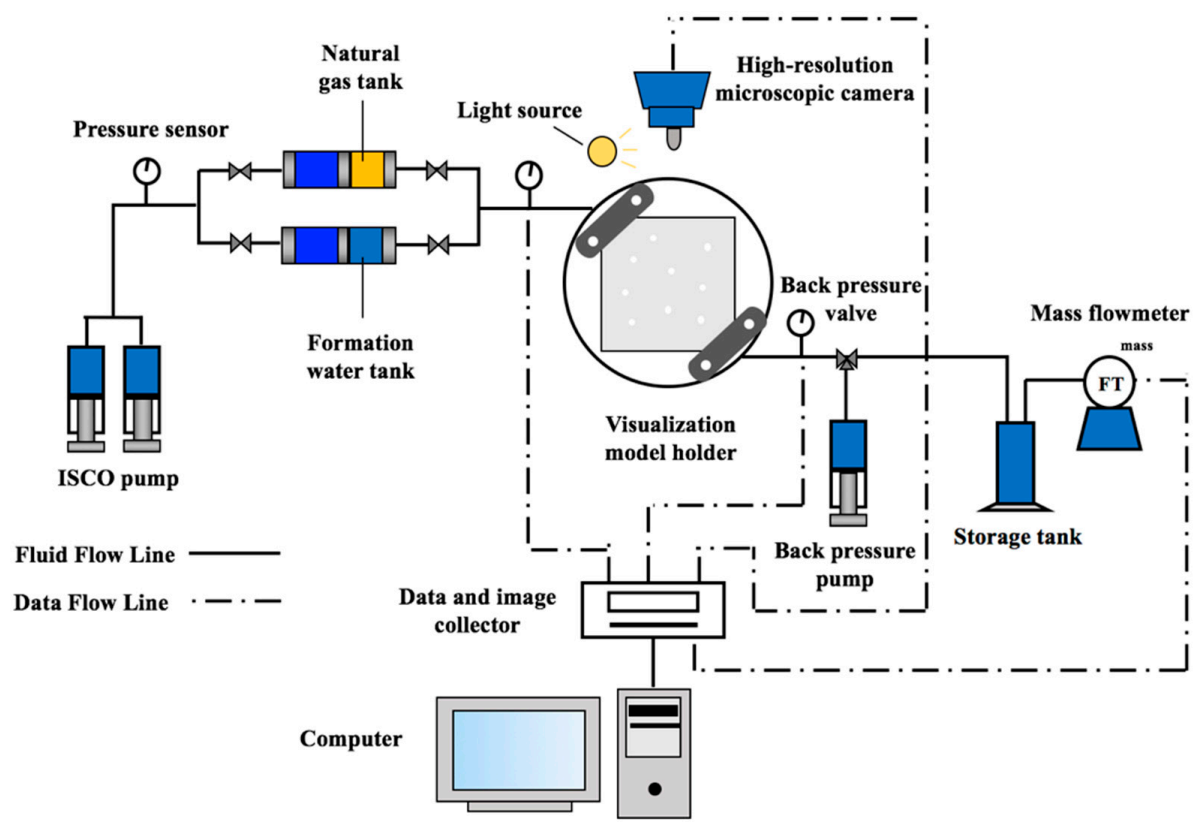

Figure 7. Schematic diagram of the two-dimensional visual simulation experiment.

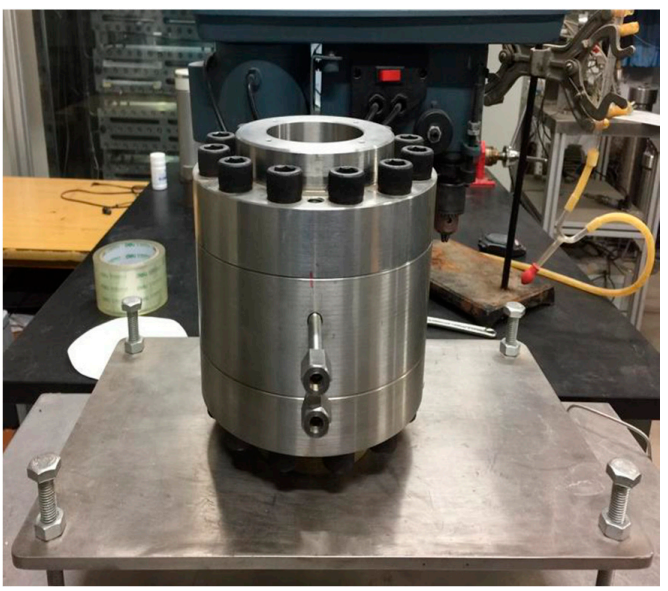

(a)

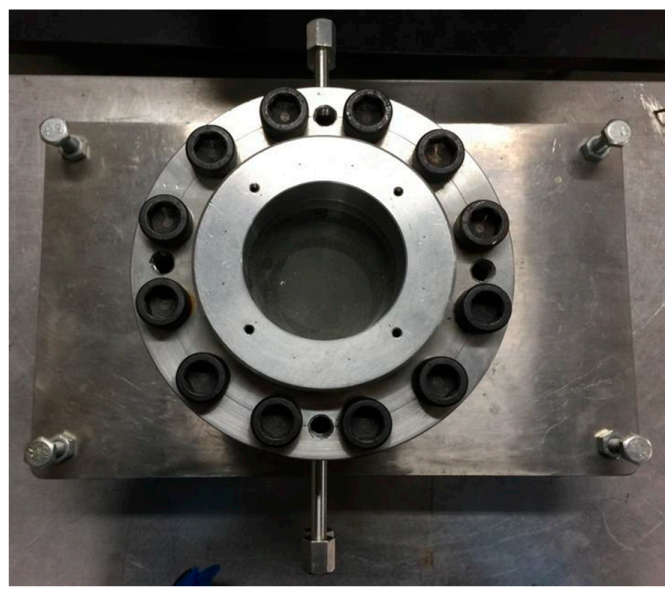

(b)

Figure 8. Appearance of the two-dimensional visual micromodel holder: (a) Overall structure; (b) Top structure. 
Table 2. Composition and properties of experimental natural gas.

\begin{tabular}{|c|c|c|c|c|c|c|c|c|c|}
\hline \multicolumn{7}{|c|}{ Percentage of Natural Gas Components (\%) } & \multirow{2}{*}{$\begin{array}{l}\text { Relative } \\
\text { Density }\end{array}$} & \multirow{2}{*}{$\begin{array}{l}\text { Pseudo-Critical } \\
\text { Pressure (MPa) }\end{array}$} & \multirow{2}{*}{$\begin{array}{l}\text { Pseudo-Critical } \\
\text { Temperature (K) }\end{array}$} \\
\hline $\mathrm{CH}_{4}$ & $\mathrm{C}_{2} \mathrm{H}_{6}$ & $\mathrm{C}_{3} \mathrm{H}_{8}$ & $\mathbf{N}_{2}$ & $\mathrm{CO}_{2}$ & $\mathrm{He}$ & $\mathrm{H}_{2} \mathrm{~S}$ & & & \\
\hline 93.13 & 0.07 & 0.01 & 0.73 & 5.01 & 0.03 & 1.02 & 0.6265 & 4.82 & 199.55 \\
\hline
\end{tabular}

\subsection{Experimental Procedure}

The procedures of the gas-drive-water visual experiment are as follows:

(1) Both the micromodel and holder were cleaned by deionized water and then dried in an oven.

(2) The micromodel was placed on the holder, and then the experimental system was exactly equipped according to Figure 7.

(3) The sealing of the experimental system was detected by injecting high-purity nitrogen gas into the system. Then, the micromodel was evacuated for $50 \mathrm{~min}$.

(4) Both the micromodel and experimental lines were heated and maintained at $80^{\circ} \mathrm{C}$, which is the original reservoir temperature.

(5) The formation water was injected into the micromodel by using an ISCO pump at $0.02 \mathrm{~mL} / \mathrm{min}$ until the saturation pressure of the micromodel reached $8 \mathrm{MPa}$.

(6) Finally, the natural gas was injected into the micromodel at the displacement differential pressures of $0.05-1.00 \mathrm{MPa}$ until no water produced in the outlet.

(7) Steps 1-6 were repeated for the other two micromodels.

Local microscopic images were sequentially captured throughout the visual experiments from the glass surface through the HLOT. The overall flow processes of the micromodels were also recorded by the DV, and then the images were intercepted from the videos at desired times. These images can be used for further quantitative characterization through the ImageJ gray analysis method.

\subsection{ImageJ Gray Analysis Method}

Different from the oil-water visual experiments investigated in previous papers, the duration of the gas-water flow experiment is too short to be measured using the conventional measurement apparatus and methods because of the high mobility of natural gas. In addition, accurate material balance calculations are difficult to perform. For example, the pore volume of a micromodel is approximately $0.07 \mathrm{~mL}$, while the volume of each injection or production port is approximately $0.1 \mathrm{~mL}$. Consequently, the four ports occupy most of the micromodel volume, which can trap amount of fluid. As a result, the application of any material balance calculation in gas-water visual experiments can lead to certain errors. In order to overcome the measurement difficulties, images intercepted from the videos throughout the visual experiments were quantitatively characterized using the ImageJ analysis method to obtain the pore volume, gas-water saturation, flow pattern and occurrence states [42]. This is a popular technique in computer science and technology, and the procedure is as follows:

(1) The pretreatment of images was primarily conducted using the Photoshop software (Adobe Photoshop CS6, Adobe Systems Software Ireland Ltd, San Jose, CA, USA) to adjust the brightness and enhance the quality. Each image takes about $2 \mathrm{~min}$ for pretreatment.

(2) The colorless gas was converted to yellow to facilitate the distinction between gas and glass particles, as presented in Figure 9a. Each image takes about 20 min for conversion.

(3) The ImageJ software was used to distinguish the gray value of the image. After setting the threshold, the pixels of the glass particles were converted to white pixels, whereas the pixels of the voids were converted to red pixels, as depicted in Figure 9b. Each image takes about $15 \mathrm{~min}$ for conversion.

(4) The area occupied by voids was calculated by counting the number of red pixels, and then the porosity of micromodel can be determined. Each image takes about $3 \mathrm{~min}$ for calculation. 
(5) Then, Photoshop and ImageJ software were used again to separate the gas from the fluid and convert the gas to yellow pixels, as shown in Figure 9c. Each image takes about $10 \mathrm{~min}$ for separation.

(6) The area occupied by gas was calculated again by counting the number of yellow pixels, and then the gas saturation can also be obtained. Each image takes about $3 \mathrm{~min}$ for calculation.

As a result, the water-gas saturation and the residual water film thickness can be obtained at any time. ImageJ gray analysis is a simple and efficient method does not require numerous computational resources.

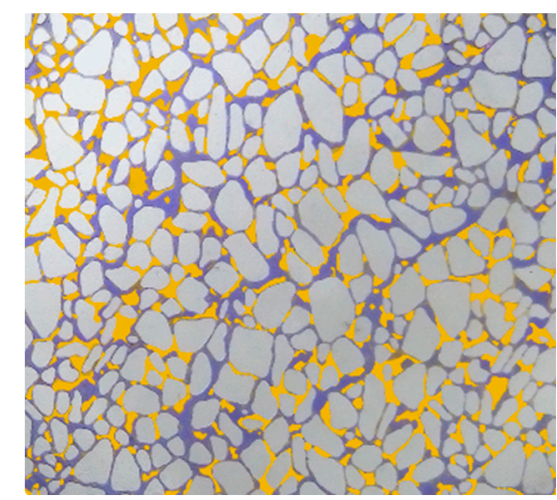

(a)

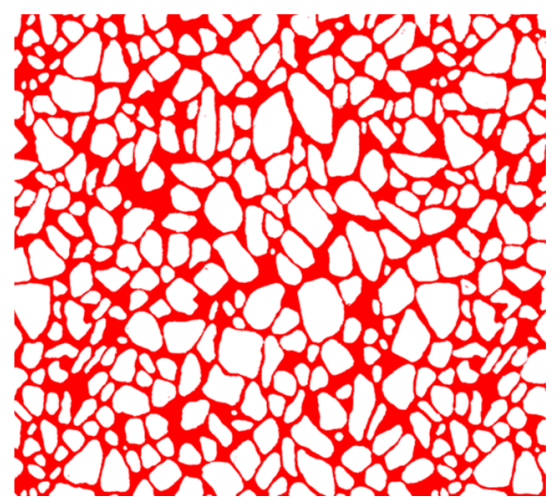

(b)

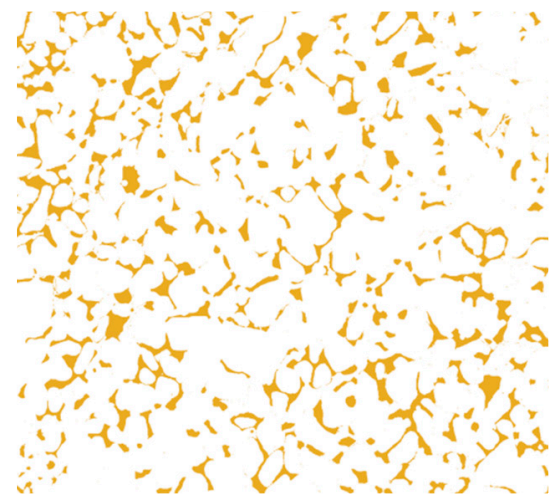

(c)

Figure 9. Schematic of quantitative characterization of images based on ImageJ gray analysis. (a) Gas-water distribution image after pretreatment; (b) Area occupied by voids; (c) Area occupied by gas.

\section{Results and Discussion}

\subsection{Formation Mechanism of Residual Water in Different Types of Reservoirs}

Gas-drive-water experiments were used to simulate the formation process of gas reservoirs and the flow process of formation water. The property of gases determines that they can enter a very small space for displacement. For the three types of micromodels, injection water preferentially enters and occupies the wall surfaces of large channels and the small channels, due to the combined effect of surface tension and capillary dimensions. Eventually, fractures, cavities, pores and throats are filled completely with injection water, while only partially saturated at dead ends and blind corners (Figures 10a, 11a, and 12a). However, the interspace of the original formation should be completely saturated with formation water according to the hydrocarbon migration and accumulation theory [43]. Therefore, the unsaturated porosity should be considered as irreducible water saturation. 
For the fracture-type micromodel, fractures are the main flow channels in the fracture-type micromodel and have a higher flow capacity than pores and cavities. Injection gas preferentially enters the large channels in porous media at the beginning of gas-drive-water process [44]. Therefore, the injection gas rapidly displaces the water in the middle part of fractures (Figure 10b), and then displaces the water in the location of small pores, fracture wrinkles and channel intersections (Figure 10c). In the later stage of gas-drive-water, the residual water adhering to the fracture walls is entrained by the continuously injection gas flow. As a result, water film becomes thin and then converges into water droplets at the intersection of fractures. Finally, these water droplets are driven out, only leaving the thin water film on fracture walls (Figure 10d). This part of residual water film can be further thinned by increasing the displacement pressure.

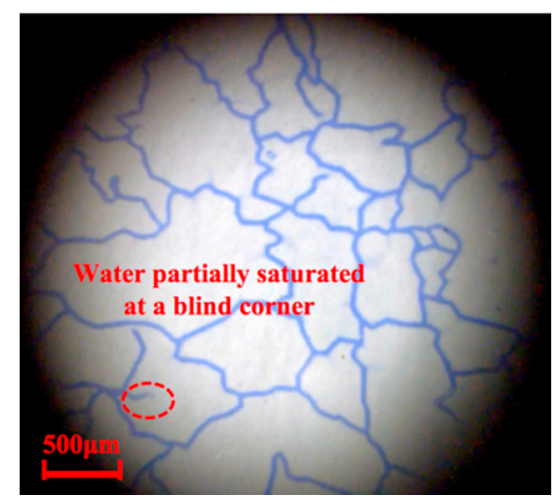

(a)

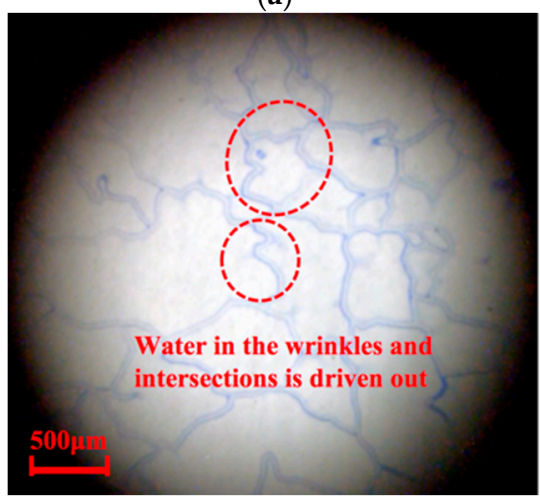

(c)

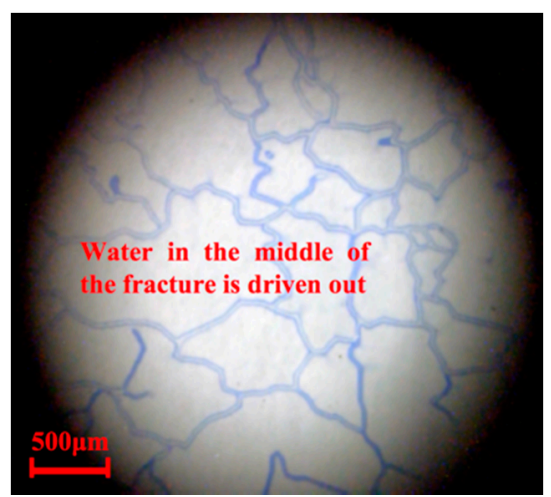

(b)

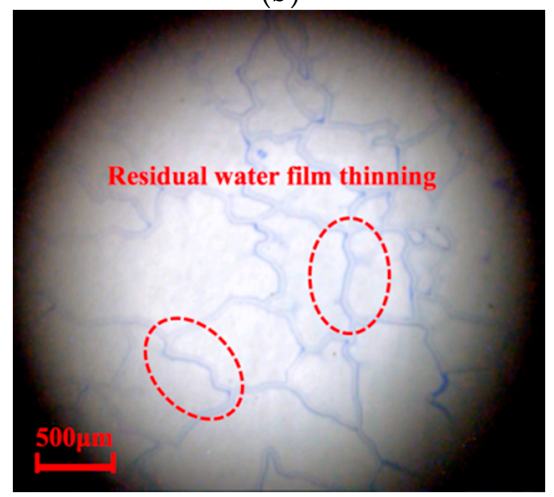

(d)

Figure 10. Gas-drive-water process of the fracture-type micromodel: (a) Initial stage; (b) Second stage; (c) Third stage; (d) Final stage.

A cavity-type micromodel is composed of small size pores and large size cavities, and its seepage capability is mainly controlled by the size and distribution of throats. The injection gas preferentially advances along the dominant flowing path, and then gradually occupies the channel space with the persistent injection of gas. As a result, some of the water in the porous medium is driven out. When the injection gas enters a cavity, a small gas-flow channel is formed around the water body of the cavity at first (Figure 11b). As the gas is continuously injected, it gradually widens the gas-flow channel and drives out the water around the water body. Eventually, a relatively rounded water mass formed in the center of the cavity. When the water mass is displaced for a long time, its shape no longer changes, demonstrating that gas under this displacement differential pressure cannot drive the water mass out any more (Figure 11c). In the later stages of gas-drive-water, the water film on the pore walls converges, and is then displaced by gas when its thickness reaches a critical state. Finally, residual water forms at slender pore-channels, narrow throat-channels and bottom of cavities (Figure 11d). 
However, the residual water mass at the bottom of cavity can become small and be partially driven out as the displacement pressure increases.

The combination structure of fractures and cavities is a unique structure of the fracture-cavity carbonate reservoirs. The injection gas promptly displaces the water in the middle of fractures to form a gas-flow channel (Figure 12b). When gas enters a cavity, it preferentially displaces the water around the cavity to create a gas-flow channel and then surrounds the water body in the cavity center (Figure 12c). Then, the central water body is continuously denuded and shrunk with the continuous gas injection. Consequently, the mobile water eroded from the water body converges into water droplets at the fracture in the cavity exit, and then it is driven out. When the water body in the cavity shrink to a certain extent and no longer changes, the residual water mass formed at the bottom of the cavity. For some cavities connected with many fractures, most of water is driven out, only forming residual water film on the cavity walls (Figure 12d). This part of residual water film or water mass can also be thinned or shrunk at high displacement pressure.

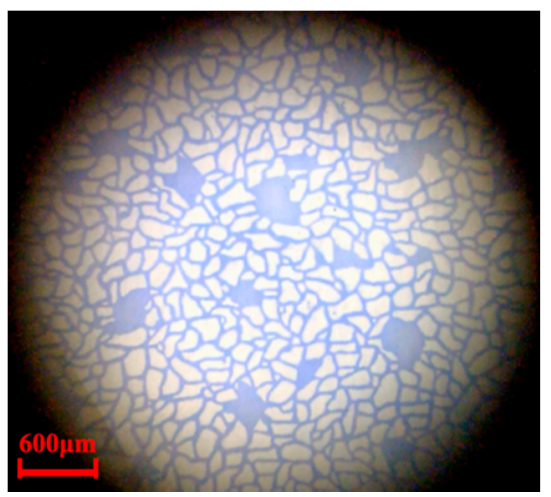

(a)

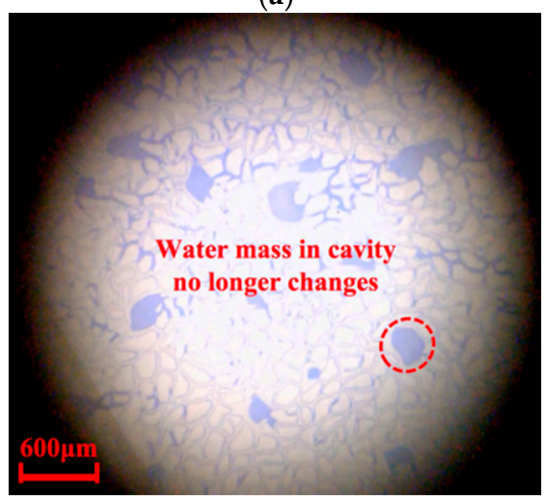

(c)

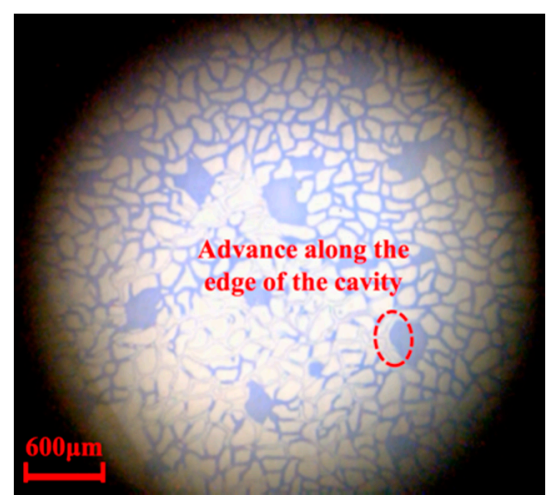

(b)

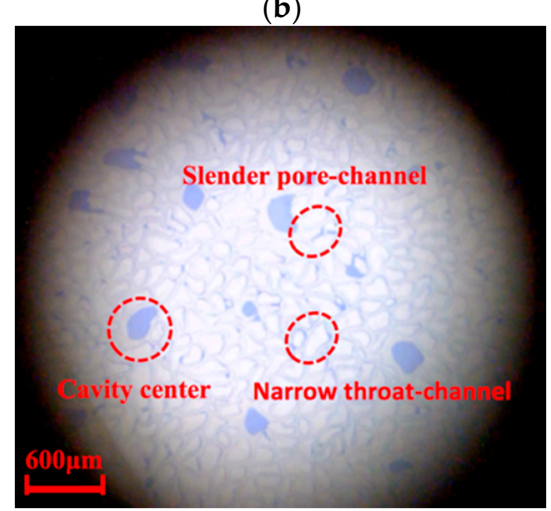

(d)

Figure 11. Gas-drive-water process of the cavity-type micromodel: (a) Initial stage; (b) Second stage; (c) Third stage; (d) Final stage. 


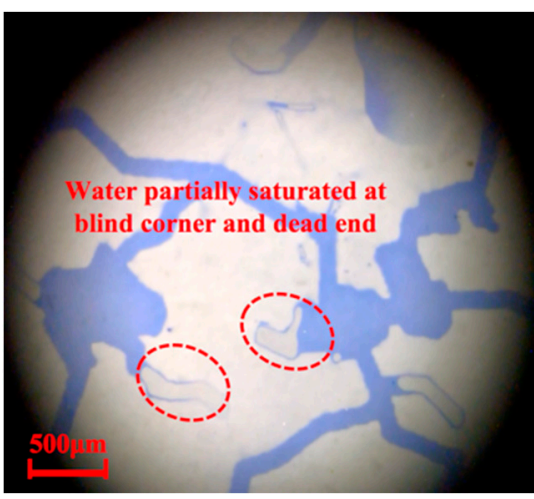

(a)

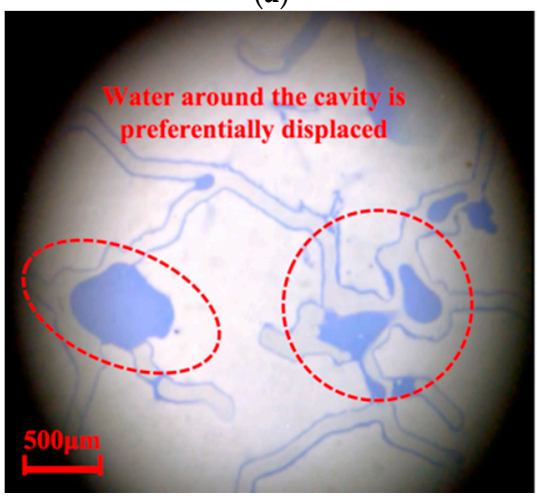

(c)

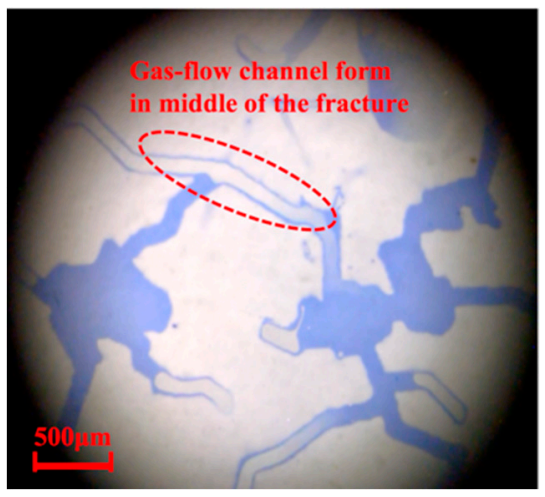

(b)

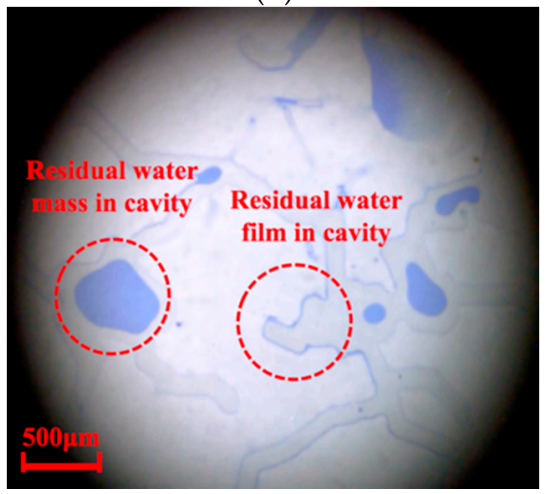

(d)

Figure 12. Gas-drive-water process of the fracture-cavity-type micromodel: (a) Initial stage; (b) Second stage; (c) Third stage; (d) Final stage.

\subsection{Occurrence States of Residual Water and Its Effect on Gas Seepage Capability}

The reservoir space is initially filled with water during the deposition of rocks, and then the original water is displaced by oil or gas during the hydrocarbon migration and accumulation. As a result, the coexistence state of oil-water or gas-water is formed [44]. This displaced and migrated water is called primary movable water. When the oil or gas reservoir is discovered, the water in reservoir space is called residual water at this moment, and the saturation of residual water is related to the reservoir forming conditions. During the development of the oil and gas fields, some residual water in the reservoir is converted into secondary movable water and then gradually produced under the displacement pressure. This part of residual water is not driven out and stranded in the reservoir space due to the migration force less than the migration resistance in the process of hydrocarbon accumulation. However, the water in reservoir space cannot be fully displaced even if the migration power is sufficient in the process of hydrocarbon migration. There is also a certain amount of residual water that distributes or remains in the blind corners of particle contact, the narrow pore-throats or adsorbed on the particle surfaces of rock skeleton. This part of residual water cannot be free to migrate under normal developing conditions, and is hence called irreducible water [3]. The classification of formation water is presented in Figure 13. 


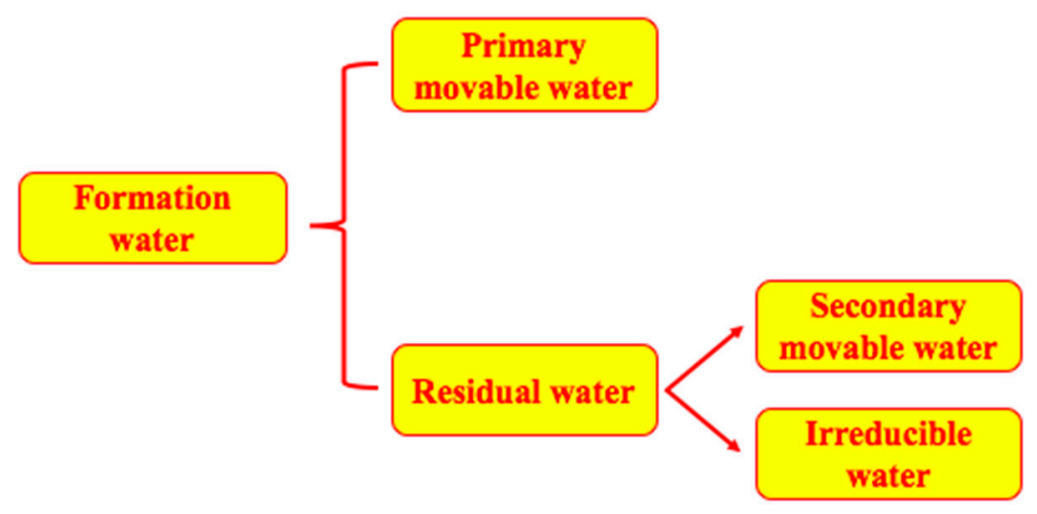

Figure 13. Classification of formation water in fracture-cavity carbonate reservoirs.

Fractures are the main flow channels in the fracture- and fracture-cavity-type micromodels [42]. The water in the middle of fractures is preferentially displaced during the gas-drive-water process. Due to the small capillary resistance, the effect of surface tension makes the residual water occurred on the wall surfaces of poorly connected fractures with the form of "thin water film" (Figure 14a). Therefore, the residual water saturation of these two micromodels is low, and the thin water film has little effect on the seepage capability of gas-phase. For a cavity-type micromodel, the residual water occurs on the particle surfaces in the form of "thick water film" under the effect of the high capillary force. Accordingly, the residual water saturation is high, which narrows the flow channel of gas-phase and increases seepage resistance. It is not easy to drive out a water film when the displacement pressure is low. However, the gas-flow can drive part of water film flow when the displacement pressure increases to a certain extent and displaces for a long time. This water then gradually become an important part of secondary movable water.

The residual water mass at the bottom of cavity is one of the major forms of residual water in the cavity- and fracture-cavity-type micromodels. When injection gas enters a cavity, it preferentially breaks through along the periphery of the water body to form and then widen the seepage channel. At the same time, the water body is denuded by the gas-flow and then converges into water droplets at the exit of the cavity. These water droplets can be driven out by the subsequent gas-flow. When the water body is displaced to a certain extent, the preferential seepage channel has been completely formed. At this point, the shape of water body no longer changes and remains in the bottom of the cavity to form the residual "water mass" (Figure 14b). The residual water mass has little effect on the seepage capability of the gas phase because there is still a wide flow channel in the upper part of cavity. The force balance of the water mass can be broken by increasing the displacement pressure. Consequently, some external water of water mass can be transformed into secondary movable water.

Since the micromodel (core sample) is hydrophilic, the gas is non-wetting phase whereas the water phase is wetting phase. Therefore, capillary force is resistance in the process of gas-drive-water. Water in the narrow throats suffers strong capillary resistance, which lead to the cutoff phenomenon in the process of gas-drive-water. Part of the water is trapped throughout the throat with the form of "water column" and blocks the seepage channel (Figure 14c). 


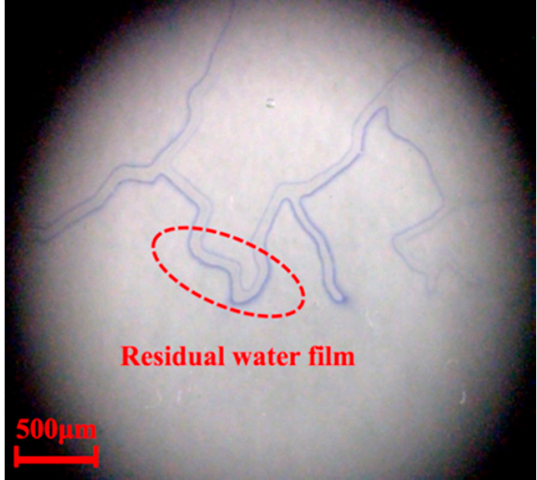

(a)

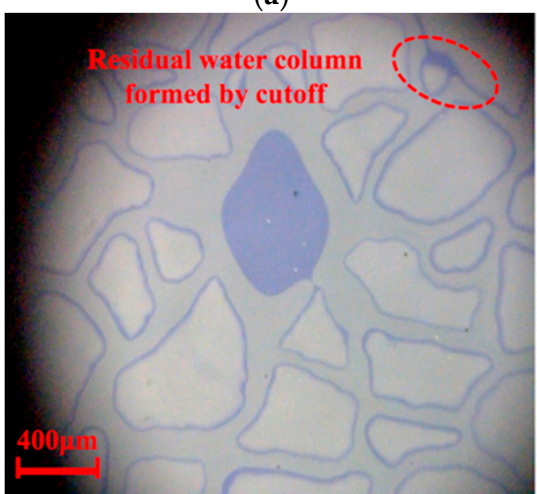

(c)

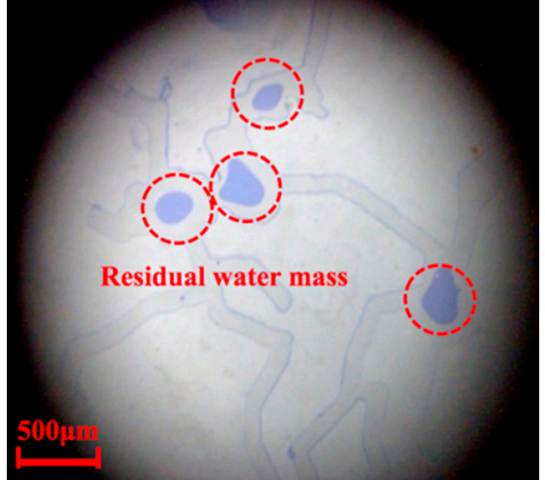

(b)

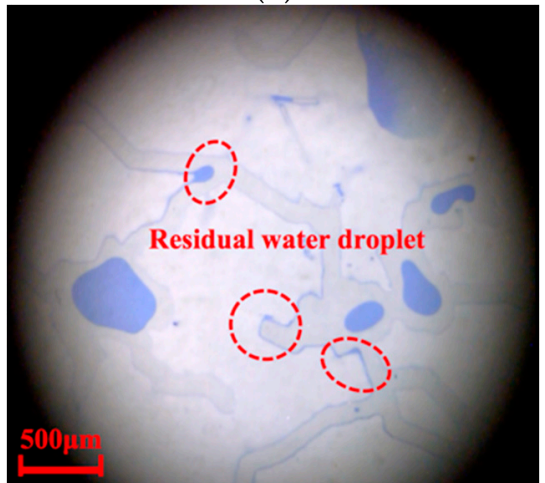

(d)

Figure 14. Occurrence states of residual water after gas-drive-water visual experiments: (a) Residual water film on the fracture walls; (b) Residual water mass at the bottom of the cavity; (c) Residual water column formed by cutoff; (d) Residual water droplet at the dead end and blind corner.

Furthermore, the large pores controlled by narrow throats are also blocked. It is one of the main reason for the sharp decrease of gas-phase permeability after water encroachment. Through the observation of the videos obtained from the visual experiment, it was found that the residual "water column" formed by cutoff phenomenon cannot flow, even under a high displacement pressure. Therefore, this residual "water column" is interpreted as irreducible water. While for the case of simultaneous existence of several pore channels, the capillary resistance in the long and narrow pore channels is much larger than that in the short and wide pore channels. As a result, the water occurs in the long and narrow pore channels needs to consume more energy to be driven out. Therefore, residual water is easily formed in the long and narrow pore channels and reduces the number of seepage channels. This part of residual water is interpreted as secondary movable water. Seepage channels cannot be formed in the dead ends or blind corners of the pores or cavities. Therefore, some of the water is trapped under gas pressure and occurs as the form of residual "water droplet" (Figure 14d). Furthermore, some of the gas may also be trapped. However, it is difficult for this part of the trapped water and gas to participate in the flow [44]. Therefore, they are interpreted as trapped gas and irreducible water. Through the above visual experimental results, it can be summarized that the residual water mainly occurs as the four forms of "water film", "water mass", "water column" and "water droplet" in the fracture-cavity carbonate gas reservoir. The main types, influencing factor and forming mechanism of different occurrence states are presented in Table 3. 
Table 3. Main types, influencing factor and forming mechanism of different type occurrence states.

\begin{tabular}{lcll}
\hline \multicolumn{1}{c}{ Occurrence States } & \multicolumn{1}{c}{ Influencing Factor } & \multicolumn{1}{c}{ Forming Mechanism } & Water Type \\
\hline $\begin{array}{l}\text { Residual thin water film } \\
\text { on the fracture walls }\end{array}$ & Surface tension & $\begin{array}{l}\text { Residual thin water film forms in } \\
\text { the wide channels because of the } \\
\text { low capillary resistance }\end{array}$ & Secondary movable water \\
\hline $\begin{array}{l}\text { Residual thick water film } \\
\text { on the fracture walls }\end{array}$ & Capillary force & $\begin{array}{l}\text { Residual thick water film forms in } \\
\text { the narrow channel because of the } \\
\text { high capillary resistance }\end{array}$ & Secondary movable water \\
\hline $\begin{array}{l}\text { Residual water mass at } \\
\text { the bottom of cavity }\end{array}$ & Displacement pressure & $\begin{array}{l}\text { The cavity is large and the } \\
\text { capillary force can be neglected; } \\
\text { the greater the displacement } \\
\text { pressure, the smaller the residual } \\
\text { water mass }\end{array}$ & Secondary movable water \\
\hline $\begin{array}{l}\text { Residual water column } \\
\text { at the narrow throat } \\
\text { channel }\end{array}$ & Jamin effect & $\begin{array}{l}\text { The Jamin effect is serious in the } \\
\text { narrow throat channel because of } \\
\text { the high capillary resistance, } \\
\text { leading the water column forms } \\
\text { by cutoff phenomenon }\end{array}$ & Irreducible water \\
\hline $\begin{array}{l}\text { Residual water column } \\
\text { at the long and narrow } \\
\text { pore channel }\end{array}$ & Capillary force & $\begin{array}{l}\text { When displacement pressure is } \\
\text { low, the water column forms in } \\
\text { the long-narrow pore channel } \\
\text { because of the high capillary } \\
\text { resistance }\end{array}$ & Secondary movable water \\
\hline $\begin{array}{l}\text { Residual water droplet at } \\
\text { the dead end and blind } \\
\text { corner }\end{array}$ & Channel connectivity & $\begin{array}{l}\text { The water can be trapped by gas } \\
\text { pressure when the channel } \\
\text { connectivity is poor }\end{array}$ & Irreducible water \\
\hline
\end{tabular}

\subsection{Quantitative Results and Analysis of ImageJ}

The experimental results obtained from the visual simulation can only be qualitatively described and analyzed. In order to quantitatively characterize the visual images at desired times, the distribution of gas-water saturation and the thickness proportion of residual water film under different displacement differential pressure were studied by the ImageJ gray analysis method.

The curves of water saturation for three micromodels were obtained through the quantitative characterization of residual water under different displacement differential pressure, and the computational formula is as follows:

$$
S_{r w}=\frac{A_{w}}{A_{v}}=\frac{N_{w}}{N_{v}}
$$

where $S_{r w}$ is the saturation of residual water; $A_{w}$ is the area of water in the micromodel, $\mu \mathrm{m}^{2} ; A_{v}$ is the area of voids in the micromodel, $\mu \mathrm{m}^{2} ; N_{w}$ is the number of water pixels in the micromodel; $N_{v}$ is the number of void pixels in the micromodel.

The quantitative results of gas-water saturation are illustrated in Figure 15. It can be seen from the figure that movable water and residual water are parameters related directly to reservoir physical property, pore structure and displacement differential pressure. For the cavity-type reservoir with worst properties, the injection gas cannot drive the water to form an effective flow when the displacement differential pressure is low. Water starts to flow only when the differential displacement pressure increases enough to overcome the capillary resistance caused by the water lock effect. This phenomenon appears as the threshold pressure in the seepage curve. For the fracture- and fracture-cavity-type micromodels, the water can flow rapidly under low displacement differential pressure due to the existence of high-permeability fractures. Therefore, there is no threshold pressure in these micromodels, and the descent rate of residual water saturation is greater than that of cavity-type micromodel. When the water in the three micromodels starts to flow, the residual water saturation decreased rapidly under the low displacement differential pressure. At this time, the displaced water comes from the fractures, the large pores with low seepage resistance and the well-connected cavities, and it is mainly composed of native movable water. The residual water saturation decreases more slowly as the displacement differential pressure increases. At this stage, the residual water in the small pores with 
large seepage resistance, the residual water film on the walls of the fractures and large pores, and the residual water mass in the bottom of cavities are displaced by gas-flow. These types of residual water are mainly composed of secondary movable water. The value of water saturation keeps constant when the displacement differential pressure increases to a certain extent, which is interpreted as the irreducible water saturation. Finally, the irreducible water saturations of fracture-, cavity- and fracture-cavity-type micromodels are $10.2 \%, 23.5 \%$ and $15.3 \%$, respectively. It can be concluded that a certain amount of irreducible water remains in cavities, and it mainly occurs at the bottom of large cavities and the small fracture-cavity system around the large cavities. This type of occurrence state is determined by the shape and collocation of the pore-cavity-fracture system [21]. In addition, the residual water saturation of the fracture-cavity-type micromodel decreases slightly slower than that of the fracture-type micromodel. This is because the resistance of water body in the cavity is high. When the injection gas enters cavity, the displacement of water body needs a higher displacement differential pressure and a longer displacement time. Therefore, the cavity can slow the overall displacement rate.

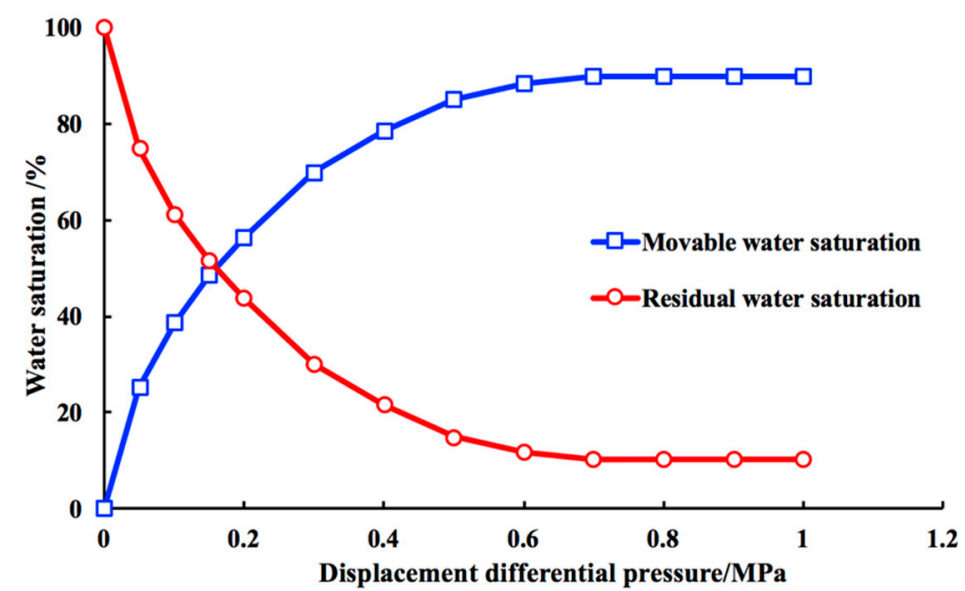

(a)

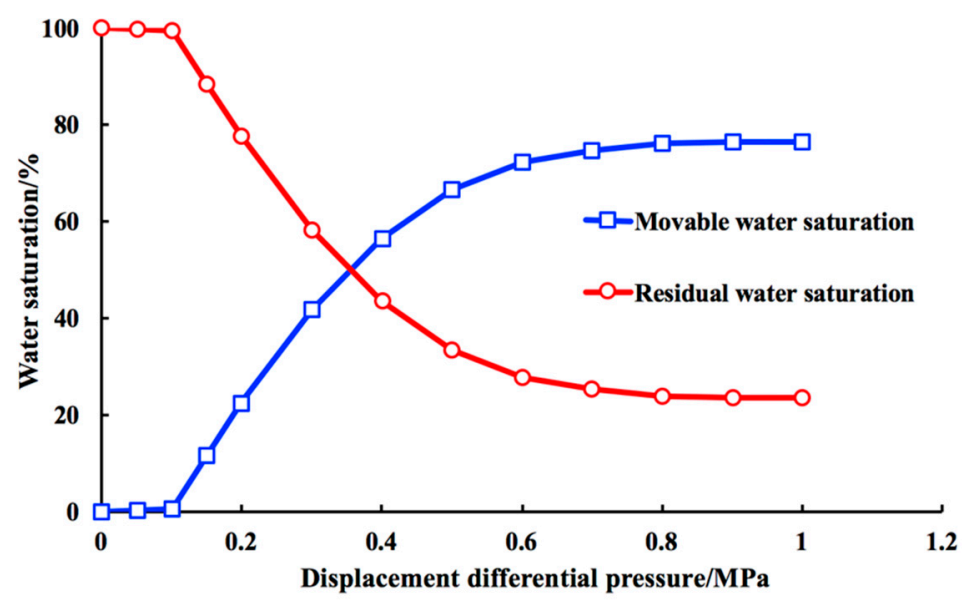

(b)

Figure 15. Cont. 


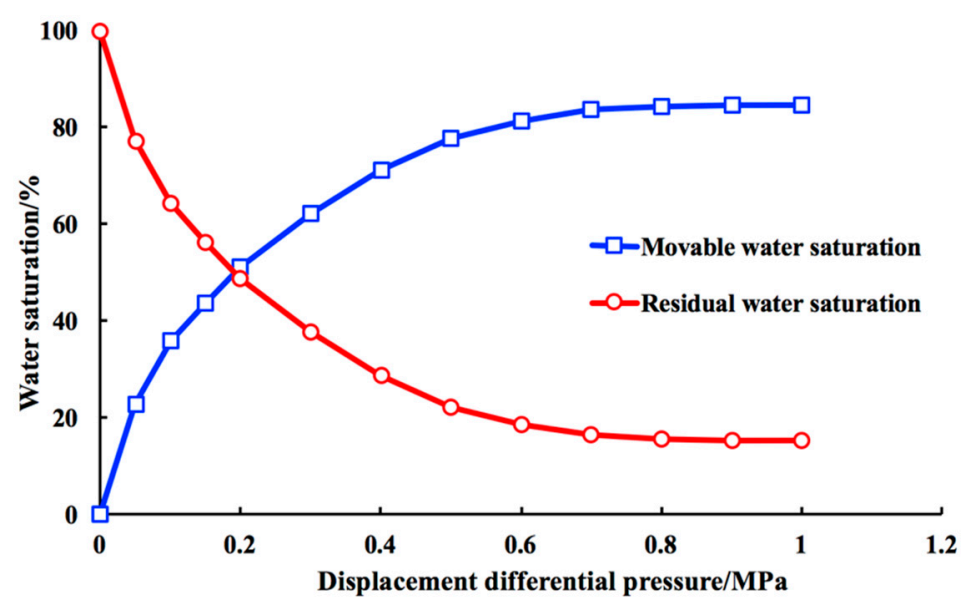

(c)

Figure 15. Water saturation versus displacement differential pressure based on the ImageJ gray analysis of the three visual micromodels. (a) Fracture type; (b) Cavity type; (c) Fracture-cavity type.

Through the gas-drive-water visual experiment, we also found that the residual water film thickness of fracture and pore walls is related not only to the channel size but also to the displacement differential pressure. In order to study the relationship among these parameters, the pore and fracture channels with different sizes in the three micromodels were selected for observation. Then the Image gray analysis was used to quantitatively characterize the proportion of residual water film thickness in the flow channel, and the computational formula is as follows:

$$
P_{w}=\frac{T_{w}}{T_{c}}=\frac{N_{w}}{N_{c}}
$$

where $P_{w}$ is the proportion of residual water film thickness in the channel; $T_{w}$ is the thickness of residual water film, $\mu \mathrm{m} ; T_{c}$ is the channel thickness of the pore and fracture, $\mu \mathrm{m} ; N_{w}$ is the pixel number of residual water film in the channel; $N_{c}$ is the pixel number of the channel.

The quantitative results of residual water film proportion are illustrated in Figure 16. It can be seen from the figure that the smaller the size of the flow channel, the larger the space occupied by the water film under the same differential pressure. As a result, the seepage capability of gas phase decreases as the effective seepage channel narrows. The proportion of residual water film increases exponentially when the size of seepage channel narrows to a certain extent. As a result, the residual water film can occupy the space of channel completely and form the "cutoff" type irreducible water at the extremely narrow throats. The proportion of water film in any size channels decreases with the increase of displacement differential pressure, and the narrower the channel, the greater the degree of reduction. However, the proportions of residual water film in any size channels keep constant and form the "thin film" type irreducible water when the displacement differential pressure increases to a certain extent. The proportion of residual water film in the fracture no longer change with the channel size after displacement for a long time under high displacement differential pressure. Therefore, the poorer the physical properties of the reservoir, the smaller the pores and throats, and the greater the capillary resistance. As a result, a higher saturation of "capillary" irreducible water is formed in these reservoirs. In addition, the finer the rock particles, the larger the rock-water contact area, resulting in a higher saturation of "thin film" irreducible water.

Through the analysis of the visual images and quantitative characterization results, several suggestions for the development of different carbonate reservoirs are can be reached. For the poreand cavity-type reservoirs with worse physical properties in fracture-cavity carbonate gas reservoirs, both the residual water saturation and irreducible water saturation are high, the effective seepage channels are narrow, the threshold pressure gradient is high, and the gas supply capability is weak [2]. 
Therefore, it is not recommended to perforate these types of reservoirs in the increasing production stage, when the reperforation can be conducted to supply the high-permeability reservoirs in the stable production stage. For the fracture- and fracture-cavity-type reservoirs with better physical properties, both the residual water saturation and irreducible water saturation are low, the effective seepage channels are wide, no threshold pressure gradient, and the gas supply capability is strong. Consequently, they can be used as the main gas production reservoirs. However, it is necessary to pay attention to the water encroachment that quickly causes water breakthrough in gas wells. It can form the hydrates and liquid loading in the wellbore, which lead to liquid phase retention and capillary imbibition in other reservoirs [42]. As a result, the gas-phase permeability is reduced and the gas supply capability of commingled production is inhibited.

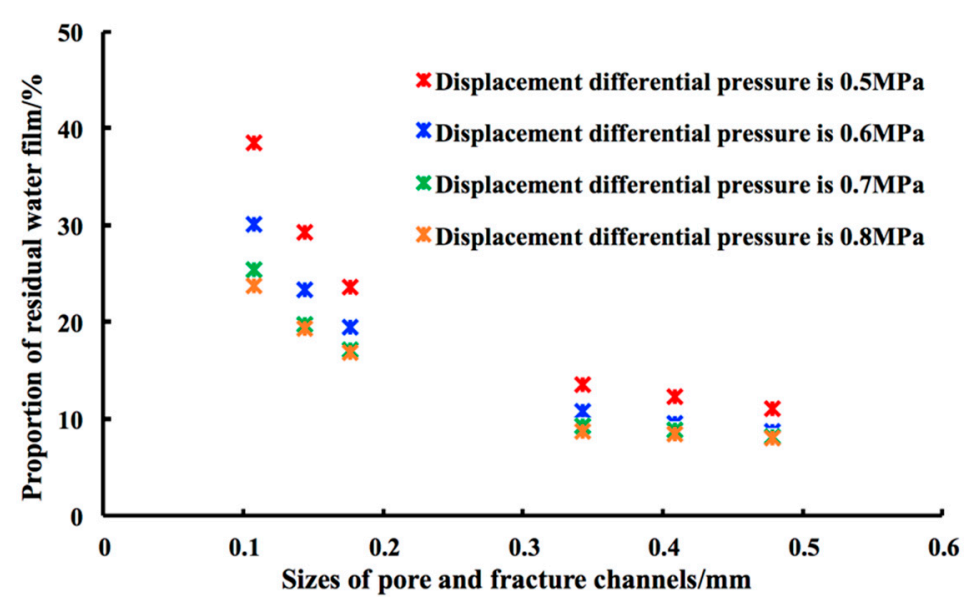

Figure 16. Proportion of residual water film in different size channels based on the ImageJ gray analysis method.

\section{Conclusions}

The creation method of three types (fracture-, cavity-, and fracture-cavity-type) of visual micromodels were first described based on the combined technique of $\mathrm{CT}$ scanning and microelectronic photolithography. These visual micromodels could approximately simulate the microstructures of multi-type reservoirs in the fracture-cavity carbonate gas reservoir. Then, the accuracy, sealability and pressure-resistant capacity of the micromodel are improved, which can intuitively investigate the process of gas-water flow, the formation mechanism of residual water, and the occurrence characteristics of formation water.

The water in multi-type gas reservoirs consists of primary movable water and residual water, and the residual water is composed of secondary movable water and irreducible water. The residual water mainly occurs in the different locations of different reservoirs with the forms of "water film", "water mass", "water column" and "water droplets". The main influencing factors of all these occurrence states are capillary force, surface tension, displacement pressure and channel connectivity.

The residual water saturation decreases rapidly under a low displacement differential pressure. In this stage, the displaced water comes from the fractures and large pores both with low seepage resistance, as well as the well-connected cavities. This water is interpreted as native movable water. The residual water saturation decreases slowly as the displacement differential pressure increases. At this time, the residual water in the small pores with large seepage resistance, the residual water film on the walls of fractures and large pores, and the residual water mass in the bottom of cavities are all displaced by gas-flow. These water is interpreted as secondary movable water. The value of water saturation keeps constant when the displacement differential pressure increases to a certain extent, and it is interpreted as the irreducible water saturation. 
The existence of water films can narrow the effective seepage channel and decrease the gas-phase seepage capability. The smaller the size of seepage channel under the same displacement differential pressure, the larger the space occupied by the water film. Furthermore, the proportion of residual water film will increase exponentially when the size of seepage channel narrows to a certain extent. Nevertheless, the proportion of water film decreases with the increase of displacement differential pressure, and the narrower the channel size, the greater the water film reduction. When the displacement differential pressure increases to a certain extent, the proportion of residual water film keeps constant, and the "thin film" irreducible water is formed.

Acknowledgments: The authors are grateful to the State Key Laboratory of Petroleum Resources and Prospecting in Beijing for their support of this work. The authors are also grateful to the National Science and Technology Major Projects of China (2016ZX05015-003), and State Key Basic Research and Development Program (2015CB250900) for their fund support. In addition, we also thank Xingli $\mathrm{Xu}$ in Shandong University, for her help in English writing.

Author Contributions: Shenglai Yang and Xian Peng designed the visual micromodels and the visual experiments; Lu Wang and Hui Deng conducted the visual experiments; Yicheng Liu and Wei Xu created three types of visual micromodels; Youjun Yan and Shenglai Yang analyzed the experimental results by ImageJ gray analysis method; Lu Wang in charge of writing and story telling; Yi Liao and Lu Wang in charge of the revision of the manuscript.

Conflicts of Interest: The authors declare no competing financial interest.

\section{References}

1. Wu, Y.S.; Di, Y.; Kang, Z.J.; Fakcharoenphol, P. A multiple-continuum model for simulating single-phase and multiphase flow in naturally fractured vuggy reservoirs. J. Pet. Sci. Eng. 2011, 78, 13-22. [CrossRef]

2. Wang, L.; Yang, S.L.; Liu, Y.C.; Xu, W.; Deng, H.; Meng, Z.; Han, W.; Qian, K. Experiments on gas supply capability of commingled production in a fracture-cavity carbonate gas reservoir. Pet. Explor. Dev. 2017, 44, 824-833. [CrossRef]

3. Wang, L.; Yang, S.L.; Meng, Z.; Chen, Y.Z.; Qian, K.; Han, W.; Wang, D.F. Time-dependent shape factors for fractured reservoir simulation: Effect of stress sensitivity in matrix system. J. Pet. Sci. Eng. 2018, 163, 556-569. [CrossRef]

4. Feng, Y.; Gray, K.E. Modeling lost circulation through drilling-induced fractures. SPE J. 2018, 23, $205-223$. [CrossRef]

5. Feng, Y.; Jones, J.F.; Gray, K.E. A review on fracture-initiation and -propagation pressures for lost circulation and wellbore strengthening. SPE Drill. Compl. 2016, 31, 134-144. [CrossRef]

6. Feng, Y.; Gray, K.E. Review of fundamental studies on lost circulation and wellbore strengthening. J. Pet. Sci. Eng. 2017, 152, 511-522. [CrossRef]

7. Hu, Y.; Shao, Y.; Lu, J.L.; Zhang, Y.F. Experimental study on occurrence models of water in pores and the influencing to the development of tight gas reservoir. Nat. Gas Geosci. 2011, 22, 176-181.

8. Wang, X.M.; Zhao, J.Z.; Liu, X.S. Occurrence state and production mechanism of formation water in tight sandstone reservoirs of Sulige area, Ordos Basin. Pet. Geol. Exp. 2012, 34, 400-405.

9. Zhu, H.Y.; Xu, X.; Gao, Y.; Hu, Y.; An, L.Z.; Guo, C.M. Occurrence characteristics of tight sandstone pore water and its influence on gas seepage: A case study from the Denglouku gas reservoir in the Changling Gas Field, Southern Songliao Basin. Nat. Gas Ind. 2014, 34, 54-58.

10. Zhu, H.Y.; Xu, X.; An, L.Z.; Guo, C.M.; Xiao, J.R. An experimental on occurrence and mobility of pore water in tight gas reservoirs. Acta Petrol. Sin. 2016, 37, 230-236.

11. Li, C.H.; Li, X.Z.; Gao, S.S.; Liu, H.X.; You, S.Q.; Fang, F.F.; Shen, W.J. Experiment on gas-water two-phase seepage and inflow performance curves of gas wells in carbonate reservoirs: A case study of Longwangmiao Formation and Dengying Formation in Gaoshiti-Moxi block, Sichuan Basin, SW China. Pet. Explor. Dev. 2017, 44, 930-938. [CrossRef]

12. Xiao, B.Q.; Zhang, X.; Wang, W.; Long, G.B.; Chen, H.X. A fractal model for water flow through unsaturated porous rocks. Fractals 2018, 26, 1840015. [CrossRef]

13. Xiao, B.Q.; Wang, W.; Fan, J.T.; Chen, H.X.; Hu, X.L.; Zhao, D.S.; Zhang, X.; Ren, W. Optimization of the fractal-like architecture of porous fibrous materials related to permeability, diffusivity and thermal conductivity. Fractals 2017, 25, 1750030. [CrossRef] 
14. Xiao, B.Q.; Chen, H.X.; Xiao, S.X.; Cai, J.C. Research on relative permeability of nanofibers with capillary pressure effect by means of fractal-monte carlo technique. J. Nanosci. Nanotechnol. 2017, 17, 6811-6817. [CrossRef]

15. Chatenever, A.; Calhoun, J.C., Jr. Visual examinations of fluid behavior in porous media-Part I. J. Pet. Technol. 1952, 4, 149-156. [CrossRef]

16. Wan, J.; Tokunaga, T.K.; Tsang, C.; Bodvarsson, G.S. Improved glass micromodel methods for studies of flow and transport in fractured porous media. Water Resour. Res. 1996, 32, 1955-1964. [CrossRef]

17. Buchgraber, M.; Al-Dossary, M.; Ross, C.M.; Kovscek, A.R. Creation of a dual-porosity micromodel for pore-level visualization of multiphase flow. J. Pet. Sci. Eng. 2012, 86-87, 27-38. [CrossRef]

18. Mohammadi, S.; Maghzi, A.; Ghazanfari, M.H.; Masihi, M.; Mohebbi, A.; Kharrat, R. On the control of glass micro-model characteristics developed by laser technology. Energy Sources Part A 2013, 35, 193-201. [CrossRef]

19. Mattax, C.C.; Kyte, J.R. Ever see a waterflood? Oil Gas J. 1961, 59, 115-128.

20. Mohammadi, S.; Ghazanfari, M.H.; Masihi, M. A pore-level screening study on miscible/immiscible displacements in heterogeneous models. J. Pet. Sci. Eng. 2013, 110, 40-54. [CrossRef]

21. Sayegh, S.G.; Fisher, D.B. Enhanced oil recovery by $\mathrm{CO}_{2}$ flooding in homogeneous and heterogeneous $2 \mathrm{D}$ micromodels. J. Can. Pet. Technol. 2009, 48, 30-36. [CrossRef]

22. Wang, J.; Dong, M.; Asghari, K. Effect of oil viscosity on heavy oil-water relative permeability curves. In Proceedings of the 15th SPE-DOE Improved Oil Recovery Symposium, Tulsa, OK, USA, 22-26 April 2006.

23. Bai, B.; Missouri-Rolla, U.O.; Liu, Y.; Coste, J.P.; and Li, L. Preformed particle gel for conformance control: Transport mechanism through porous media. SPE Reserv. Eval. Eng. 2007, 10, 176-184. [CrossRef]

24. Wang, Y.Z.; Liu, H.Q.; Pang, Z.X.; Gao, M. Visualization study on plugging characteristics of temperature-resistant gel during steam flooding. Energy Fuels 2016, 30, 6968-6976. [CrossRef]

25. Wu, Z.B.; Liu, H.Q.; Pang, Z.X.; Wu, Y.L.; Wang, X.; Liu, D.; Gao, M. A visual investigation of enhanced heavy oil recovery by foam flooding after hot water injection. J. Pet. Sci. Eng. 2016, 147, 361-370. [CrossRef]

26. Soudmand-Asli, A.; Ayatollahi, S.S.; Mohabatkar, H.; Zareie, M.; Shariatpanahi, S.F. The in situ, microbial enhanced oil recovery in fractured porous media. J. Pet. Sci. Eng. 2007, 58, 161-172. [CrossRef]

27. Mosavat, N.; Torabi, F. Micro-optical analysis of carbonated water injection in irregular and heterogeneous pore geometry. Fuel 2016, 175, 191-201. [CrossRef]

28. George, D.S.; Hayat, O.; Kovscek, A.R. A microvisual study of solution-gas-drive mechanism in viscous oils. J. Pet. Sci. Eng. 2005, 46, 101-119. [CrossRef]

29. Chen, H.; Yang, S.L.; Ren, S.S.; Yu, D.H.; Li, F.F.; Lu, H.; Zhang, X. Crude Oil Displacement Efficiency of Produced Gas Re-injection. Int. J. Green Energy 2013, 10, 566-573. [CrossRef]

30. Hatiboglu, C.U.; Babadagli, T. Experimental and visual analysis of co- and counter-current spontaneous imbibition for different viscosity ratios, interfacial tensions, and wettabilities. J. Pet. Sci. Eng. 2010, 70, 214-228. [CrossRef]

31. Doryani, H.; Malayeri, M.R.; Riazi, M. Visualization of asphaltene precipitation and deposition in a uniformly patterned glass micromodel. Fuel 2016, 182, 613-622. [CrossRef]

32. Smith, J.D.; Chatzis, I.; Ioannidis, M.A. A new technique to measure the breakthrough capillary pressure. J. Can. Pet. Technol. 2005, 44, 25-31. [CrossRef]

33. Yun, W.; Kovscek, A.R. Microvisual investigation of polymer retention on the homogeneous pore network of a micromodel. J. Pet. Sci. Eng. 2015, 128, 115-127. [CrossRef]

34. Romero-Zeron, L.B.; Kantzas, A. The effect of wettability and pore geometry on foamed-gel-blockage performance. SPE Reserv. Eval. Eng. 2007, 10, 150-163. [CrossRef]

35. Mackay, E.J.; Henderson, G.D.; Tehrani, D.H.; Danesh, A.; Herlot-Watt, U. The importance of interfacial tension on fluid distribution during depressurization. SPE Reserv. Eval. Eng. 1997, 1, 408-415. [CrossRef]

36. Bahralolom, I.M.; Orr, F.M. Solubility and extraction in multiple-vontact miscible displacements: Comparison of $\mathrm{N}_{2}$ and $\mathrm{CO}_{2}$ flow visual experiments. SPE Reserv. Eng. 1988, 3, 213-219. [CrossRef]

37. Schneider, M.; Osselin, F.; Andrews, B.; Rezgui, F.; Tabeling, P. Wettability determination of core samples through visual rock and fluid imaging during fluid injection. J. Pet. Sci. Eng. 2011, 78, 476-485. [CrossRef]

38. Lei, H.; Yang, S.L.; Zu, L.H.; Wang, Z.L.; Li, Y. Oil Recovery performance and $\mathrm{CO}_{2}$ storage potential of $\mathrm{CO}_{2}$ water-alternating-gas injection after continuous $\mathrm{CO}_{2}$ injection in a multilayer formation. Energy Fuels 2016, 30, 8922-8931. [CrossRef] 
39. Lei, H.; Yang, S.L.; Qian, K.; Chen, Y.; Li, Y.; Ma, Q.Z. Experimental investigation and application of the asphaltene precipitation envelope. Energy Fuels 2015, 29, 6920-6927. [CrossRef]

40. Chen, H.; Zhang, X.S.; Chen, Y.; Tang, H.; Mei, Y.; Li, B.W.; Shen, X. Study on pressure interval of near-miscible flooding by production gas Re-injection in QHD offshore oilfield. J. Pet. Sci. Eng. 2017, 157, 340-348. [CrossRef]

41. Chen, H.; Yang, S.L.; Zhang, X.S.; Ren, S.S.; Dong, K.; Li, Y.; Meng, Z.; Wang, L.; Lei, H.; Ma, Q.Z. Study of phase behavior and physical properties of a natural gas reservoir with high carbon dioxide content. Greenh. Gases-Sci. Technol. 2016, 6, 428-442. [CrossRef]

42. Wang, L.; Yang, S.L.; Peng, X.; Deng, H.; Meng, Z.; Qian, K.; Wang, Z.L.; Lei, H. An improved visual investigation on gas-water flow characteristics and trapped gas formation mechanism of fracture-cavity carbonate gas reservoir. J. Nat. Gas Sci. Eng. 2018, 49, 213-236. [CrossRef]

43. Li, M.C.; Li, J. "Dynamic trap": A main action of hydrocarbon charging to form accumulations in low permeability-tight reservoir. Acta Pet. Sin. 2011, 31, 718-722.

44. Dai, J.Y.; Li, J.T.; Wang, B.G.; Pan, R. Distribution regularity and formation mechanism of gas and water in the western area of Sulige gas field, NW China. Pet. Explor. Dev. 2012, 39, 560-566. [CrossRef]

(C) 2018 by the authors. Licensee MDPI, Basel, Switzerland. This article is an open access article distributed under the terms and conditions of the Creative Commons Attribution (CC BY) license (http:/ / creativecommons.org/licenses/by/4.0/). 